\section{Chemical Pilot Plant Practice}

By Donald G. Jordan. (Chemical Engineering and Tochnology Library, Vol. 1.) Pp. viii + 152. (New York : Interscience Publishers, Inc.; London : Interscience Publishers, Ltd., 1955.) 3.50 dollars.

7 HE opening chapter of this small book contains 1 an interesting discussion of the general factors to be taken into account before building a pilot plant; these include, among others, cost estimation, the size and location of the plant, and the type of men required to operate it. It is also emphasized that pilot plants are not always required for checking and correcting the theories used for the design of full-scale plant, but may be used for small-scale production in order that the properties and commercial value of new materials may be studied and sufficient quantities of byproducts may be obtained for the assessment of their utility. An analysis of the scale-up problem follows, and a chapter on the handling of materials on the pilot scale. In the next two chapters, various types of reactors and separation processes are discussed, and finally the important subjects of report writing and cost estimation are dealt with in detail.

Very little space is given up to theory, as it is assumed that readers are already conversant with the theoretical side; at the same time it would be unfair to describe the book as consisting of 'hints and tips'. Although these abound, they are presented as part of a reasoned discussion in which it is clear that the author is writing from practical experience. All who are concerned in any way with pilot plant are recommended to read this book, for very fow will fail to derive some benefit from it.

\section{H. E. Watson}

\section{General School Physics}

Heat and Light. By R. Stone, N. Bronner and J. Lawrence. (Grammar School Series.) Pp. ix +374 . (London: English Universities Press, Ltd., 1955.) 9s. $6 d$.

WITH the senior science master of Manchester Wrammar School as editor and part author, one former member of the staff collaborating, and another participating with advice, this excellent textbook for middle school use has the hall-mark of thoroughness and sound teaching that would be expected. It should help pupils to a real understanding of these parts of the subject, and stimulate their awareness of the application of physical principles in the world around them.

Mr. R. Stone's predecessor, the late H. S. Newbould, used to caution his younger colleagues not to try to teach too much; and there is always the temptation in elementary work to carry one's own interests to a level a little above the pupils' heads. Here the authors have not concealed their enthusiasm, but they have taken the greatest care to keep within the capacity of fifth-form boys in their explanations.

The diagrams, drawn with the clarity and simplicity of blackboard figures, are unusually good. In optics, great attention is given to ray diagrams, and this is clearly the method that the authors prefer at this stage for the solution of problems. Many teachers also may feel that algebraic formulæ are best deferred until a later stage, when they have to be repeated in any event ; those addicted to their use will certainly approve the authorg' analysis of the schoolboy's difficulties, and may find an answer to their own in the treatment advocated here.
Textile Testing

By James Lomsx. Third edition. Pp. xiii $+218+14$ plates. (London and New York : Longmans, Green and Co., Ltd., 1956.) 30s. net.

$1 \mathrm{HE}$ arrangement and content of the third edition of this book are substantially the same as in the second edition. New material has been introduced in a few places in the text and, in seven pages of "additional notes", at the end. An introduction has been added. It is to be regretted that the author has not taken the opportunity of including descriptions of yarn-irregularity meters, methods of yarn inspec. tion, or the newer automatic single-thread testers. Other important omissions are the use of the thread-crimp tester, the determination of threads per inch, cloth handle, creasability and tearing strength.

The author illustrates most of the calculations by examples worked out in detail. Such assistance is a luxury in a book of this kind. On the other hand, there is a lack of scientific and technological background, and of advice on the proper application of the methods described. In any future edition this balance should be corrected. British Standards Handbook No. 11 (to which the author frequently refers) now provides a manual for nearly all the routine work of a textile laboratory, and a modern text-book on textile testing could well be written with the aim of providing the basic information required to understand the techniques and apply them intelligently.

The book cannot be recommended unreservedly to a young student as his only guide because of a number of statements that are either inaccurate or inadequate.

H. M. TAYLOR

\section{The Mechanical Properties of Textile Fibres}

Edited by R. Meredith. (Deformation and Flow: Monographs on the Rheological Behaviour of Natural and Synthetic Products.) Pp. xii $+333+4$ plates. (Amsterdam: North-Holland Publishing Company, 1956.) n.p.

EXTILE fibres are a class of technologically important materials with interesting mechanical properties : they are non-linear, strongly time-dependent and sensitive to humidity and temperature. Their various chemical structures, and the physical and chemical treatments they receive in processing and manufacture, result in many, variations on the general pattern of behaviour.

Dr. R. Meredith and his co-authors Dr. L. Peters and Mr. H. J. Woods have written a welcome book in which they describe the mechanical properties of the various fibres and report the current position in the interpretation of those properties in relation to fibre structure. Cellulose, protein and synthetic fibres are discussed in separate sections which follow similar patterns for ease of cross-reference. There are chapters on structure, stress relaxation and creep, load-extension curves and on dynamic properties, each section ending with a chapter on properties which have received attention because of their practical importance: the strength of cellulose fibres, setting effects in keratin fibres, and resilience and creasing of synthetic fibres. Separate chapters are devoted to reaction-rate theory in two sections, and the theory of linear viscoelasticity is treated in connexion with stress relaxation and dynamic properties. There is a comprehensive bibliography. 